\title{
Akt1 genetic variants confer increased susceptibility to thyroid cancer
}

\author{
Thomas Crezee $1,2, *$, Mirela Petrulea ${ }^{3, *}$, Doina Piciü,4, Martin Jaeger ${ }^{2,5}$, Jan W A Smit ${ }^{5}$, Theo S Plantinga ${ }^{1,5}$, \\ Carmen E Georgescu ${ }^{3,6}$ and Romana Netea-Maier ${ }^{2,5}$
}

'Department of Pathology, Radboud University Medical Center, Nijmegen, The Netherlands

${ }^{2}$ Radboud Institute for Molecular Life Sciences (RIMLS), Radboud University Medical Center, Nijmegen, The Netherlands

${ }^{3}$ Department of Endocrinology, luliu Hatieganu University of Medicine and Pharmacy, Cluj-Napoca, Romania

${ }^{4}$ Department of Nuclear Medicine and Endocrine Tumors, Institute of Oncology 'Prof. Dr. Ion Chiricuta', Cluj-Napoca, Romania

${ }^{5}$ Division of Endocrinology, Department of Internal Medicine, Radboud University Medical Center, Nijmegen, The Netherlands

${ }^{6}$ Endocrinology Clinic, Cluj County Emergency Hospital, Cluj-Napoca, Romania

Correspondence should be addressed to R Netea-Maier: romana.netea-maier@radboudumc.nI

*(T Crezee and M Petrulea contributed equally to this work)

\begin{abstract}
The PI3K-Akt-mTOR pathway plays a central role in the development of non-medullary thyroid carcinoma (NMTC). Although somatic mutations have been identified in these genes in NMTC patients, the role of germline variants has not been investigated. Here, we selected frequently occurring genetic variants in AKT1, AKT2, AKT3, PIK3CA and MTOR and have assessed their effect on NMTC susceptibility, progression and clinical outcome in a Dutch discovery cohort (154 patients, 188 controls) and a Romanian validation cohort (159 patients, 260 controls). Significant associations with NMTC susceptibility were observed for AKT1 polymorphisms rs3803304, rs2494732 and rs2498804 in the Dutch discovery cohort, of which the AKT1 rs3803304 association was confirmed in the Romanian validation cohort. No associations were observed between PI3K-Akt-mTOR polymorphisms and clinical parameters including histology, TNM staging, treatment response and clinical outcome. Functionally, cells bearing the associated AKT1 rs3803304 risk allele exhibit increased levels of phosphorylated Akt protein, potentially leading to elevated signaling activity of the oncogenic Akt pathway. All together, germline encoded polymorphisms in the PI3K-AktmTOR pathway could represent important risk factors in development of NMTC.
\end{abstract}

\section{Key Words}

non-medullary thyroid cancer

- susceptibility

- PI3K/Akt/mTOR

- genetic variation

\section{Background}

In recent years, the incidence of non-medullary thyroid cancer (NMTC) has steadily increased $(1,2,3,4)$. Although most NMTC patients have a favorable prognosis, $20-30 \%$ of patients with locally advanced or metastatic disease is confronted with long-term disease and increased risk of death as no curative treatment options are available $(5,6,7)$.

The intracellular proteins PI3K, Akt and mTOR are part of a central signaling pathway in NMTC tumorigenesis by facilitating signal transduction to induce angiogenesis, metabolic reprogramming, proliferation and invasion of tumor cells $(5,8)$. Patients with Cowden's disease, an autosomal dominant multiple hamartoma tumor syndrome caused by inactivating germline mutations in the PTEN gene and leading to constitutive activation of the PI3K-Akt-mTOR pathway, are at risk to develop several benign and malignant tumors, among which also NMTC $(9,10,11)$. The important role of the PI3K-AktmTOR pathway in this respect has been confirmed by the identification of somatic driver mutations in the encoding PI3KCA, AKT1, AKT2, AKT3 and MTOR genes in NMTC tumors, particularly in those having a poor prognosis https://ec.bioscientifica.com https://doi.org/10.1530/EC-20-0311 (c) 2020 The authors Published by Bioscientifica Ltd

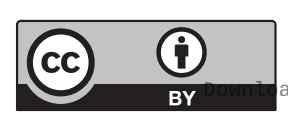

This work is licensed under a Creative Commons Attribution 4.0 International License. ded from Bioscientifica.com at $04 / 26 / 2023$ 12:42:21AM 
$(12,13,14,15,16)$. The approximate prevalence of these mutations varies from $1-2 \%$ in papillary thyroid cancer (PTC) up to $15-25 \%$ in anaplastic thyroid cancer (ATC) (6, 17). Furthermore, PI3K and mTOR targeted therapy has been observed to achieve beneficial effects by inhibiting NMTC proliferation and dedifferentiation, partly by activation of autophagy, providing the rationale for application of novel treatment modalities targeting this oncogenic pathway $(18,19,20,21,22)$.

The PI3K kinase, encoded by the PIK3CA gene, is a protein directly downstream of receptor tyrosine kinases. Upon receptor activation, the signal is transmitted to PI3K and subsequently transferred to Akt by phosphorylation. Mammalian cells express three closely related Akt isoforms: Akt1 $(\mathrm{PKB} \alpha)$, Akt2 $(\mathrm{PKB} \beta)$ and Akt3 $(\mathrm{PKB} \gamma)$, all encoded by different genes. Whereas Akt1 is ubiquitously expressed, expression of Akt2 and Akt3 is restricted to certain tissues $(23,24)$. After phosphorylation of Akt isoforms by PI3K, the mTOR kinase is phosphorylated, leading to activation of downstream driving protein synthesis, proliferation and invasion of NMTC $(5,8,25,26)$.

Although somatic mutations have been identified at low frequencies, the role of germline variants in genes encoding PI3K, Akt and mTOR in the pathogenesis and clinical outcome of NMTC has not been studied so far. For the present study, we therefore hypothesized that PI3K, Akt and mTOR germline variants influence tumorigenesis and progression of NMTC in a similar fashion as somatically occurring mutations in the same genes.

\section{Materials and methods}

\section{Study subjects}

Patients with histologically confirmed NMTC who visited the Department of Endocrinology at the Iuliu Hatieganu University of Medicine and Pharmacy Cluj-Napoca or the Institute of Oncology Cluj-Napoca (IOCN), Romania and the outpatient clinic at the Division of Endocrinology of the Department of Internal Medicine, Radboud University Medical Center, Nijmegen, The Netherlands were asked to provide blood for genetic testing. In total, 154 consecutive Dutch NMTC patients (collected between 2009 and 2010, discovery cohort) and 159 Romanian NMTC patients (collected between 2014 and 2015, validation cohort) were enrolled in the study. Total thyroidectomy was performed in all cases in addition to modified radical lymph node neck dissections in patients with clinically or radiologically confirmed nodal metastases. NMTC diagnosis and histological classification was performed by experienced thyroid cancer pathologists. RAI (I-131) ablation of residual thyroid tissue was performed 4-6 weeks after surgery. Patients were repeatedly treated with RAI to reach remission, if indicated. Cured disease was defined according to institutional cut-off values of TSH stimulated thyroglobulin $(\mathrm{Tg},<1 \mathrm{pmol} / \mathrm{L}$ in the Dutch patients and $<0.04 \mathrm{ng} / \mathrm{mL}$ in the Romanian patients) in the absence of anti-Tg antibodies and no evidence of loco-regional disease or distant metastasis on the whole body iodine scans (WBS) and/or neck ultrasonographic examinations at 6-9 months after RAI ablation. Tumor recurrence was defined as new evidence of loco-regional disease or distant metastasis after successful primary therapy. Current disease status was defined as in remission in case of undetectable unstimulated Tg (according to the institutional cut-off) in the absence of anti-Tg antibodies and no evidence of loco-regional disease or distant metastases at the last follow-up visit. Persistent disease was defined as detectable $\mathrm{Tg}$ and/or evidence of loco-regional disease or distant metastases. Recurrent disease was defined as new evidence, biochemical (e.g. Tg becoming detectable after having been undetectable) and/or radiological, of loco-regional disease or distant metastases. Histological, clinical and follow-up data were retrieved from the patients' medical records and are shown in Table 1. In addition, 188 Dutch and 260 Romanian healthy, genetically unrelated individuals, having no evidence of NMTC or other malignancies were recruited as population-based control subjects.

\section{Genotyping}

Single nucleotide polymorphisms (SNP) were selected based on population frequency, previously published associations with human diseases and/or known functional effects on protein function or gene expression $(27,28,29,30,31,32)$ (Table 2). After obtaining informed consent, blood was drawn from the cubital vein of participants into EDTA collection tubes and subjected to DNA extraction using the GeneJET ${ }^{\text {тм }}$ Whole Blood Genomic DNA Purification Mini Kit (Fermentas, Thermo Fisher Scientific) according to the manufacturer's instructions. Until further analysis, DNA samples were stored at $-20^{\circ} \mathrm{C}$. TaqMan SNP Genotyping assays (Life Technologies) designed with two specific probes and primers for each variant were utilized for genotyping the SNPs in PIK3CA, AKT1, AKT2, AKT3 and MTOR (Table 2). Ten nanograms of genomic DNA were amplified by quantitative PCR (qPCR) in a 7300 Real-Time PCR System

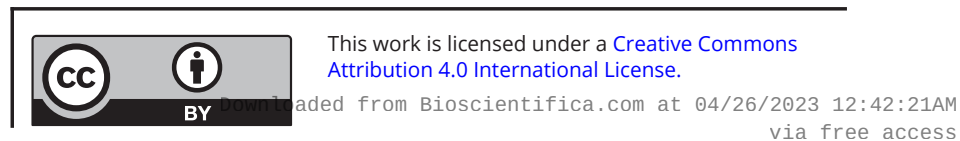


Table 1 Distribution of clinicopathological characteristics and treatment in the Dutch and Romanian non-medullary thyroid carcinoma (NMTC) cohorts.

\begin{tabular}{|c|c|c|c|}
\hline \multirow[b]{2}{*}{ Variables } & $\begin{array}{c}\text { Romanian NMTC } \\
\text { cohort }\end{array}$ & $\begin{array}{l}\text { Dutch NMTC } \\
\text { cohort }\end{array}$ & \multirow[b]{2}{*}{ P-values } \\
\hline & \multicolumn{2}{|c|}{ No. (\%) } & \\
\hline Patients & 159 & 154 & \\
\hline $\begin{array}{l}\text { Age in years } \\
(\text { mean } \pm \text { s.D. })\end{array}$ & $52( \pm 14)$ & $39( \pm 13)$ & 0.24 \\
\hline Gender (F/M) & $136 / 23$ & $115 / 39$ & 0.02 \\
\hline \multicolumn{4}{|l|}{ Tumor histology } \\
\hline PTC & $113(71.1)$ & $106(68.8)$ & \\
\hline FTC & $37(23.3)$ & $37(24.0)$ & 0.75 \\
\hline FVPTC & $9(5.7)$ & $10(6.5)$ & \\
\hline PDTC & 0 & $1(0.6)$ & \\
\hline \multicolumn{4}{|l|}{ T-stage } \\
\hline $\mathrm{T} 1$ & $77(48.4)$ & $45(29.2)$ & \\
\hline $\mathrm{T} 2$ & $26(16.4)$ & $51(33.1)$ & 0.001 \\
\hline T3 & 49 (30.8) & $25(16.2)$ & \\
\hline $\mathrm{T} 4$ & $7(4.4)$ & $12(7.8)$ & \\
\hline Tx & $0(0)$ & $21(13.6)$ & \\
\hline \multicolumn{4}{|l|}{$\mathrm{N}$-stage } \\
\hline No & 95 (59.7) & $80(52.0)$ & \\
\hline N1 & $40(25.2)$ & $51(33.1)$ & 0.28 \\
\hline $\mathrm{Nx}$ & $24(15.1)$ & $23(14.9)$ & \\
\hline \multicolumn{4}{|l|}{ M-stage } \\
\hline MO & 122 (76.7) & $106(68.8)$ & \\
\hline M1 & $11(6.9)$ & $4(2.6)$ & 0.01 \\
\hline $\mathrm{Mx}$ & $26(16.4)$ & $44(28.6)$ & \\
\hline \multicolumn{4}{|l|}{$\begin{array}{l}\text { Cumulative RAI } \\
\text { activity (mCi) }\end{array}$} \\
\hline $30-100$ & $96(60.4)$ & $39(25.3)$ & \\
\hline $100-200$ & $28(17.6)$ & 55 (35.7) & 0.001 \\
\hline$\geq 200$ & $35(22.0)$ & $60(39.0)$ & \\
\hline Persistent disease & 65 (40.9) & $67(43.5)$ & 0.64 \\
\hline
\end{tabular}

FTC, follicular thyroid cancer; FVPTC, follicular-variant papillary thyroid cancer; PDTC, poorly differentiated thyroid cancer; PTC, papillary thyroid cancer; RAI, radioactive iodide.
(Life Technologies), under standard conditions. The realtime PCR included an initial denaturation step at $95^{\circ} \mathrm{C}$ for $10 \mathrm{~min}$, followed by 40 cycles at $95^{\circ} \mathrm{C}$ for $15 \mathrm{~s}$ and then at $60^{\circ} \mathrm{C}$ for $1 \mathrm{~min}$. Quality control was performed by duplicating samples within and across plates and by the incorporation of positive and negative control samples.

\section{PBMC isolation and Western blotting}

For isolation of peripheral blood mononuclear cells (PBMCs), venous blood was drawn from the cubital vein of healthy volunteers into $10 \mathrm{~mL}$ EDTA tubes (Monoject). The mononuclear cell fraction was obtained by density centrifugation of blood diluted 1:1 in pyrogen-free saline over Ficoll-Paque (Pharmacia Biotech). Cells were washed twice in saline and suspended in culture medium (RPMI, Invitrogen) supplemented with gentamicin $10 \mu \mathrm{g} / \mathrm{mL}$, L-glutamine $10 \mathrm{mM}$ and pyruvate $10 \mathrm{mM}$. Cells were counted in a Coulter counter (Coulter Electronics) and the number was adjusted to $5 \times 10^{6}$ cells $/ \mathrm{mL}$. For Western blotting, cells were incubated with either culture medium (negative control) or with E. coli lipopolysaccharide (LPS, $100 \mathrm{ng} / \mathrm{mL}$, Sigma) for $30 \mathrm{~min}$, a well established activator of Akt signaling $(33,34)$. For western blotting of (phosphorylated) Akt protein, $5 \times 10^{6}$ cells were lysed in $40 \mu \mathrm{L}$ of lysis buffer (50 mM Tris (pH 7.4), 150 $\mathrm{mM} \mathrm{NaCl}, 2$ mM EDTA, 2 mM EGTA, 10\% glycerol, $1 \%$ Triton X-100, $40 \mathrm{mM} \beta$-glycerophosphate, $50 \mathrm{mM}$ sodium fluoride, $200 \mathrm{mM}$ sodium vanadate, $10 \mathrm{mg} / \mathrm{mL}$ leupeptin, $10 \mathrm{mg} / \mathrm{mL}$ aprotinin, $1 \mathrm{mM}$ pepstatin $\mathrm{A}$, and $1 \mathrm{mM}$ phenylmethylsulfonyl fluoride). The homogenate was frozen and then thawed and centrifuged at $4^{\circ} \mathrm{C}$ for $3 \mathrm{~min}$ at $14,000 \boldsymbol{g}$, and the supernatant was mixed with a loading buffer containing dithiothreitol, incubated at

Table 2 Selection of genotyped SNPs and TaqMan SNP genotyping assays for genotyping of polymorphisms in genes encoding components of the Akt-mTOR-PI3K pathway, including references of previous studies that revealed important genetic associations of these SNPs with cancer susceptibility or outcome.

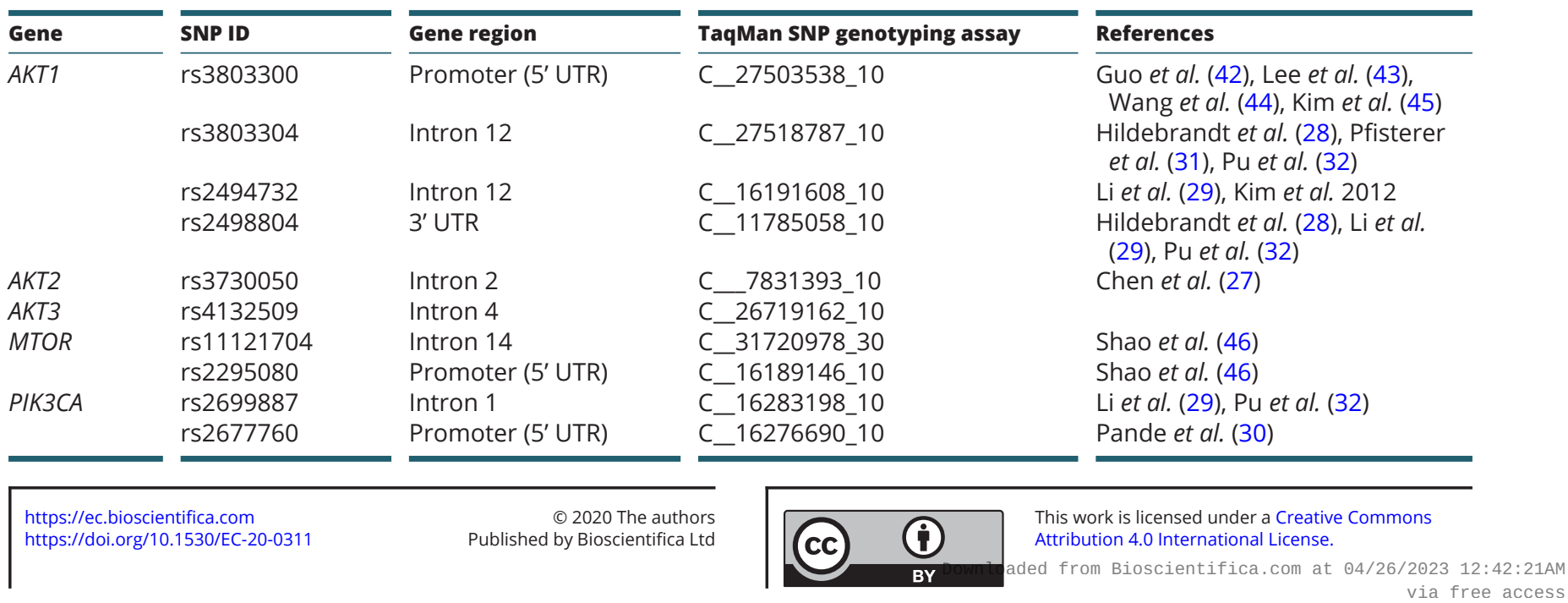


$95^{\circ} \mathrm{C}$ for $15 \mathrm{~min}$, and taken for western blot analysis. Equal amounts of protein were subjected to SDS-PAGE using $10 \%$ polyacrylamide gels. After SDS-PAGE, proteins were transferred to nitrocellulose membrane $(0.2 \mathrm{~mm})$. The membrane was blocked with $5 \%$ (wt/vol) milk powder in TBS/Tween 20 for $1 \mathrm{~h}$ at room temperature, followed by incubation overnight at $4^{\circ} \mathrm{C}$ with a pAkt S473 antibody (1:1000, Cell Signalling \#9018) or total Akt antibody (1:1000, Cell Signalling \#2938) in 5\% BSA in TBS/Tween 20 or with a $\beta$-actin antibody (loading control, 1:1000, A2066; Sigma) in 5\% milk powder in TBS/Tween 20. After overnight incubation, the blots were washed three times with TBS/Tween 20 and then incubated with horseradish peroxidase-conjugated swine anti-rabbit antibody at a dilution of $1: 5000$ in $5 \%$ (wt/vol) milk powder in TBS/ Tween 20 for $1 \mathrm{~h}$ at room temperature. After being washed three times with TBS/Tween 20, the blots were developed with ECL (GE Healthcare) according to the manufacturer's instructions.

\section{Statistical analysis}

Genotypes and allele frequencies were calculated and the Hardy-Weinberg equilibrium was assessed using a goodness-of-fit $X^{2}$-test for biallelic markers. The odds ratios (ORs) and 95\% CI of the association between genotype frequencies and NMTC susceptibility in addition to clinicopathological characteristics and treatment outcomes were analyzed using logistic regression models. In addition, $\chi^{2}$ analysis and Fisher's exact test were applied to determine whether tumor size, cumulative RAI activity (subdivided as 30-100 mCi (1.1-3.8 GBq), $101-200 \mathrm{mCi}$ (3.8-7.4 GBq) or $\geq 200 \mathrm{mCi}(>7.4 \mathrm{GBq})$ ) and disease status after thyroidectomy plus radio-ablation were associated with the genotype of the analyzed genes. All statistical analyses were carried out with SPSS for statistical computing and graphics. Differences in protein amounts detected by western blot were analyzed using the MannWhitney $U$ test. Overall, statistical tests were two-sided and a $P$-value below 0.05 was considered statistically significant.

\section{Results}

\section{PI3K-Akt-mTOR pathway SNPs and susceptibility to NMTC}

To assess the effects of genetic variation in PI3K-AktmTOR genes on susceptibility to NMTC, several SNPs were selected based on previously published associations with human diseases and/or known functional effects on protein function or gene expression. The genotypes corresponding to these SNPs were determined in the Dutch discovery cohort (154 patients, 188 healthy controls) and in the Romanian validation cohort (159 patients, 260 healthy controls). Table 1 summarizes the main clinical and demographical characteristics of the selected Dutch and Romanian NMTC patients. Distribution of gender, tumor size staging, metastasis staging and cumulative RAI activity were significantly different between the Dutch and Romanian patient cohorts. The distribution of PIK3CA, $A K T 1, A K T 2, A K T 3$ and MTOR genotypes among the Dutch and Romanian cohorts are presented in Tables 3 and 4, respectively. These results demonstrate the association of the rs3803304, rs2494732 and rs2498804 polymorphisms in $A K T 1$ with NMTC susceptibility in the Dutch discovery cohort by applying different genetic association models. Importantly, in the Romanian validation cohort the AKT1 rs3803304 polymorphism was confirmed as genetic risk factor for NMTC in the dominant model. Of note, genotype frequencies in both NMTC patients and controls study populations were in accordance with that expected under the Hardy-Weinberg equilibrium.

\section{PI3K-Akt-mTOR pathway SNPs and clinical outcome of NMTC}

Within the NMTC study populations recruited in The Netherlands and Romania, the impact of PIK3CA, $A K T 1, A K T 2, A K T 3$ and MTOR genotypes on the clinical postoperative treatment response and outcome of NMTC patients was investigated. These analyses revealed that none of the investigated polymorphisms in the PI3KAkt-mTOR pathway were associated with worse clinical manifestation of NMTC in any of the cohorts regarding histology, TNM staging, RAI treatment response and clinical outcome (Supplementary Tables 1 and 2, see section on supplementary materials given at the end of this article).

\section{Functional consequences of AKT1 rs3803304 polymorphism for pAkt and total Akt protein expression in PBMCs}

The observed genetic associations of the AKT1 rs3803304 polymorphism with NMTC susceptibility in both cohorts and of the AKT1 rs2494732 and rs2498804 polymorphisms in only the Dutch cohort suggest that these polymorphisms could influence Akt expression

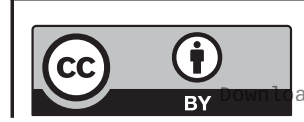

This work is licensed under a Creative Commons Attribution 4.0 International License. ded from Bioscientifica.com at 04/26/2023 12:42:21AM 


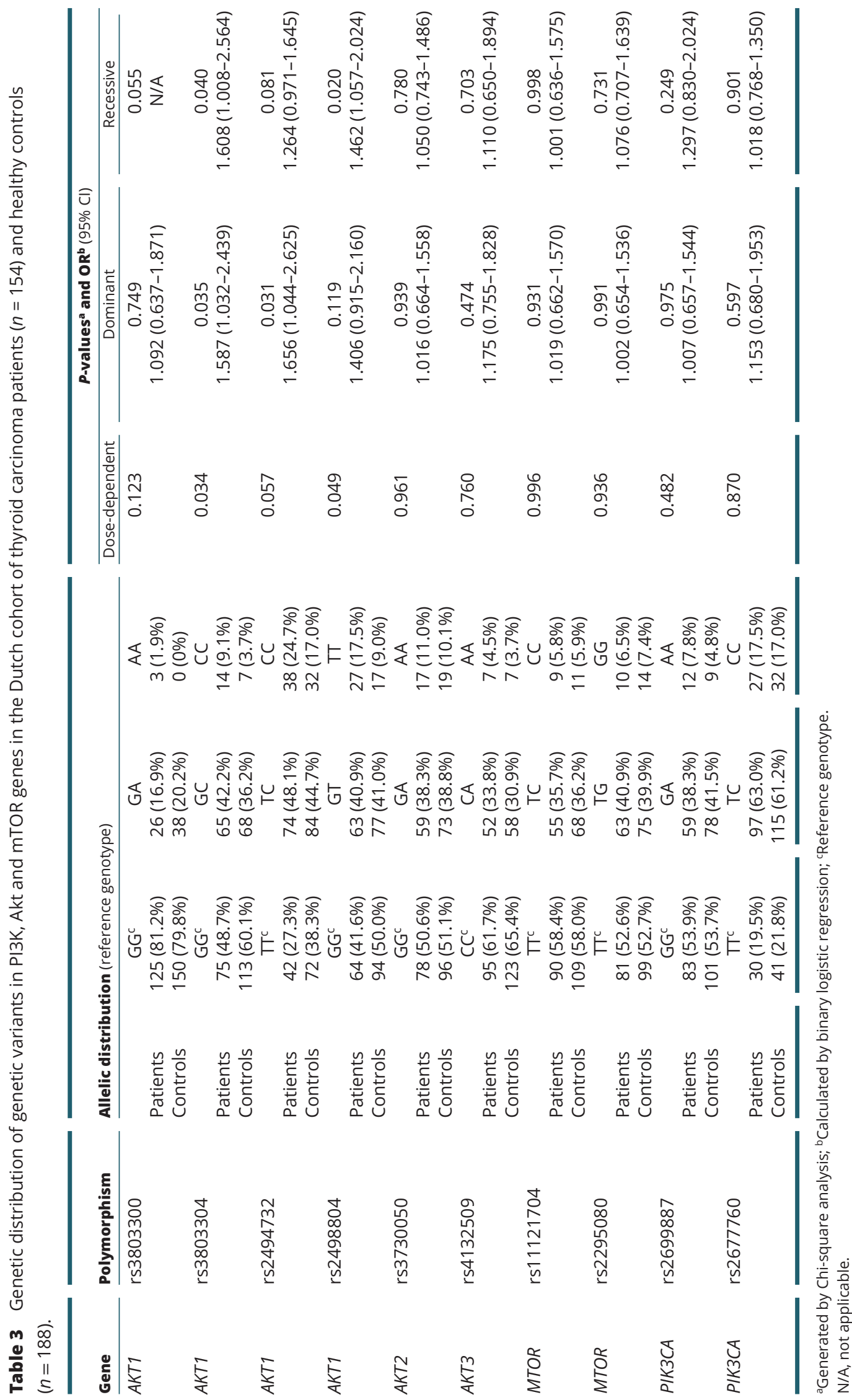




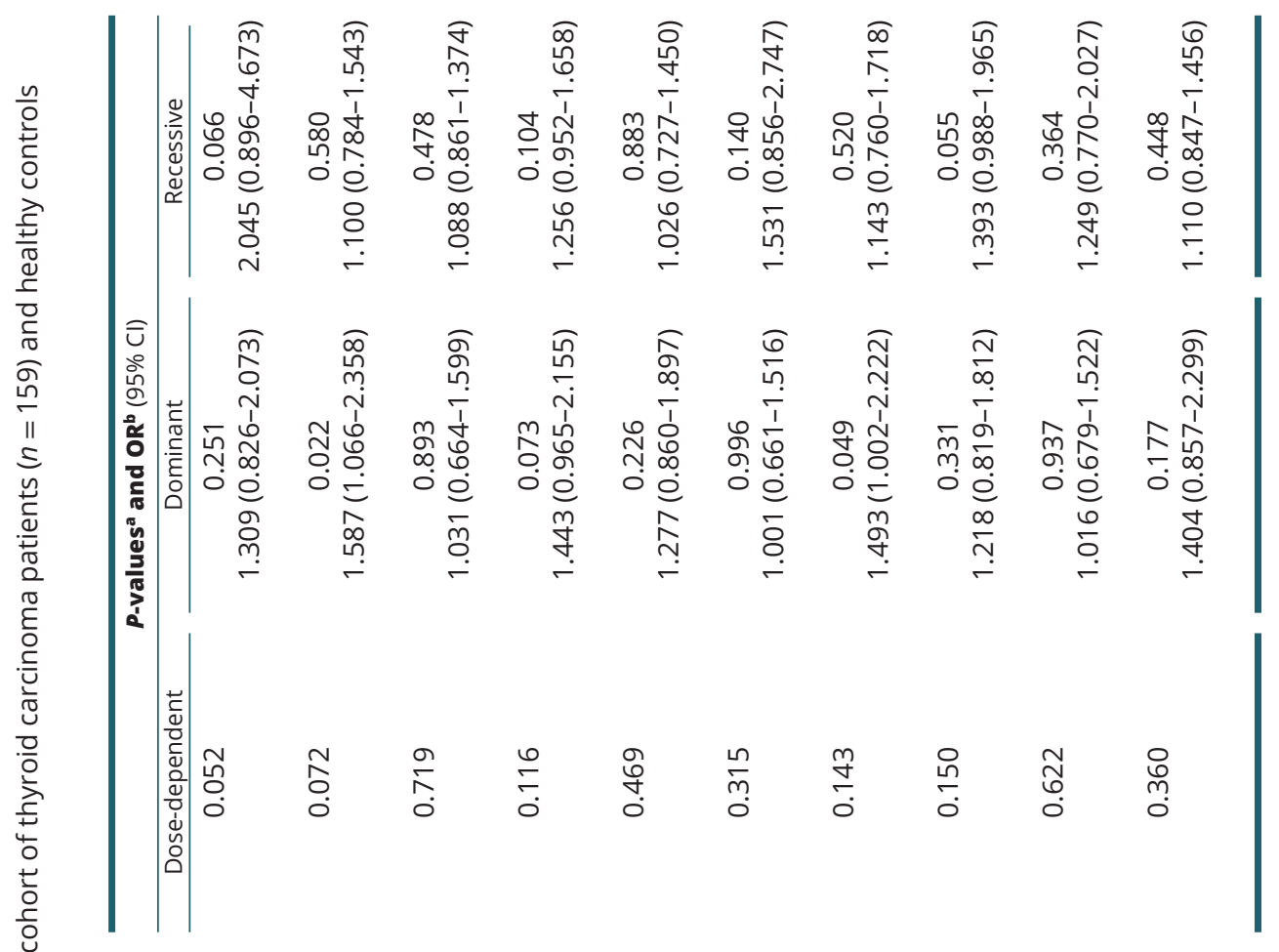

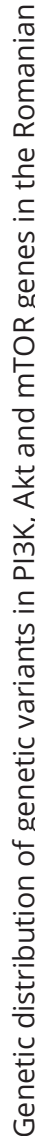

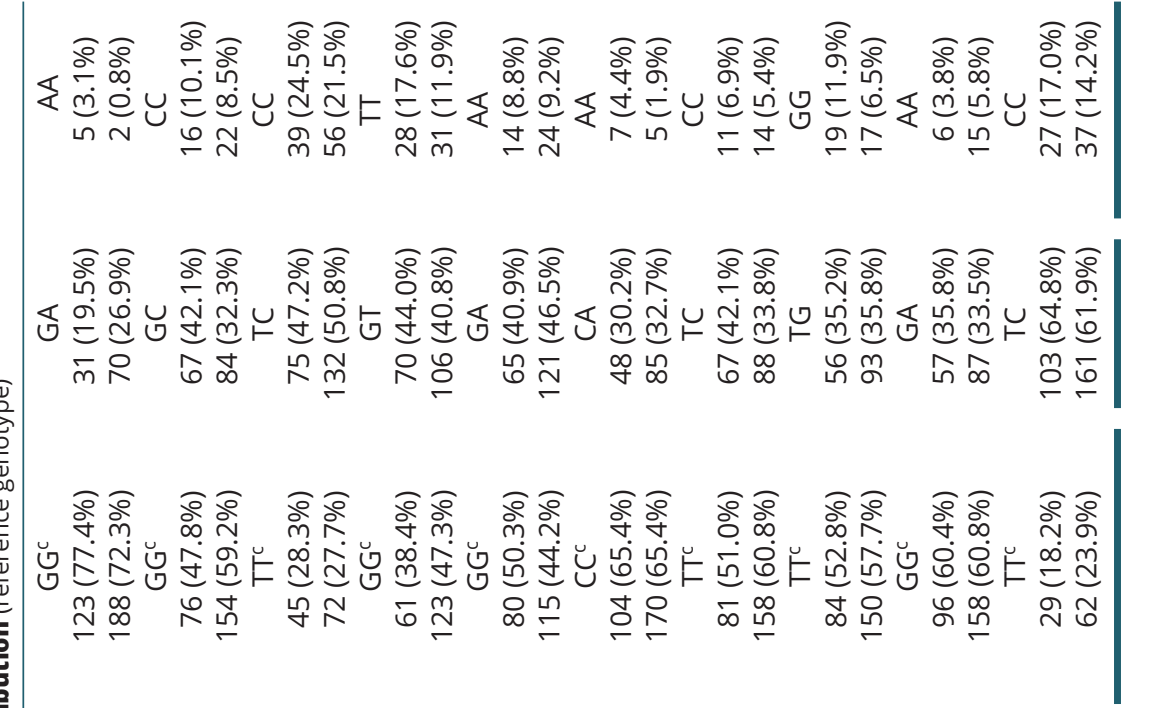

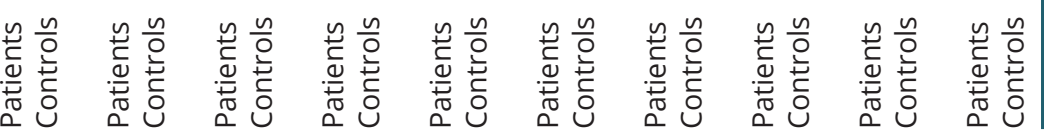


or function. To assess the potential functional effects of these polymorphisms, healthy individuals were stratified for AKT1 rs3803304, AKT1 rs2494732 or AKT1 rs2498804 genotypes and their PBMCs were tested for differential levels of phosphorylated and total Akt protein, either in the unstimulated condition or after treatment with LPS for $30 \mathrm{~min}$. Since individuals homozygous for the AKT1 rs3803304 minor allele are rare, only subjects either WT or heterozygous for the AKT1 rs3803304 minor allele could be included. The results indicate that no significant differences were apparent in total Akt expression between the genotypes. Interestingly, however, the amount of phosphorylated Akt is elevated in the individuals heterozygous for the AKT1 rs3803304 risk allele in both the unstimulated and LPS-stimulated condition as compared to WT subjects. In contrast, no differences in phosphorylated Akt are apparent between WT and homozygous AKT1 rs2494732 or AKT1 rs2498804 genotypes in either unstimulated or LPS-stimulated conditions (Fig. 1A and B).

\section{Discussion}

In recent years, the major oncogenic pathways have been elucidated that drive tumor initiation and progression in NMTC, which mainly comprise the RAS-RAF-MEK-ERK and PI3K-AKT-mTOR signaling pathways $(6,35)$. Although the contribution of somatic mutations in the activation of oncogenic signaling through these pathways has been well-established, the influence of germline variants on these pathways is still poorly characterized. The present study was performed to assess the effect of germline variants in the oncogenes PIK3CA, AKT1, AKT2, AKT3 and $M T O R$ on NMTC susceptibility and clinical outcome. For this, a Dutch discovery cohort and a Romanian validation cohort were gathered, consisting of NMTC patients and healthy unrelated controls, that allowed the assessment of potential genetic associations of selected germline polymorphisms with susceptibility to NMTC and with its clinical presentation, treatment response and patient outcome.

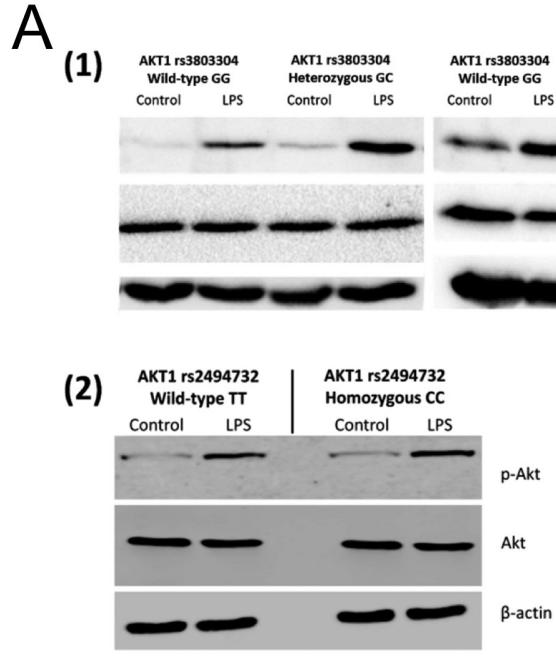

B

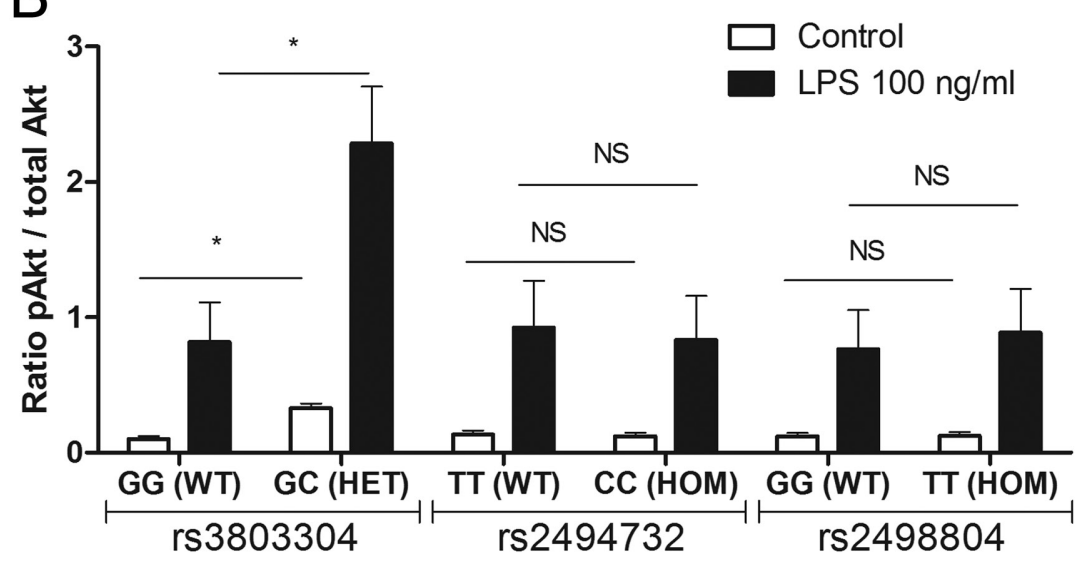

Figure 1

(A) Western blot detection of Akt and p-Akt proteins in PBMCs from individuals either (1) WT or heterozygous for AKT1 rs3803304 polymorphism ( $n=3)$, (2) WT or homozygous for AKT1 rs2494732 polymorphism $(n=1)$ or (3) WT or homozygous for AKT1 rs2498804 polymorphism $(n=1)$. Cells were left untreated or stimulated with $100 \mathrm{ng} / \mathrm{mL}$ LPS for $30 \mathrm{~min}$. Detection of $\beta$-actin served as loading control. Representative of four independent experiments and per experiment two donors per genotype group. Figures represent cropped images. (B) Quantification of pAkt/Akt ratios obtained by Western blots as depicted in (A). Data are mean \pm S.E.M. ( ${ }^{*} P$-values $<0.05$ ) are generated by MannWhitney $U$ tests, $n=4$ ). https://ec.bioscientifica.com https://doi.org/10.1530/EC-20-0311 (c) 2020 The authors Published by Bioscientifica Ltd

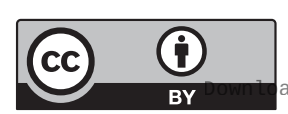

This work is licensed under a Creative Commons Attribution 4.0 International License. 
Interestingly, by the present study polymorphisms in the $A K T 1$ gene were shown to be significantly associated with NMTC susceptibility in the Dutch discovery cohort and the Romanian validation cohort. Whereas three $A K T 1$ polymorphisms (rs3803304, rs2494732 and rs2498804) were identified as statistically significant in the Dutch cohort, one of these, the rs3803304 polymorphism, was confirmed in the Romanian cohort. As opposed to polymorphisms in genes encoding PI3K, Akt2, Akt3 and mTOR, these results suggest major consequences of AKT1 polymorphisms for Akt function, especially rs3803304, in modulating the activity of the PI3K-AktmTOR signaling pathway. Importantly, this genetic association was observed in both cohorts despite the statistically significant differences in clinical parameters between the Dutch and Romanian patient cohorts listed in Table 1. For the other $A K T 1$ polymorphisms that were only significantly associated with NMTC susceptibility in the Dutch cohort, it cannot be excluded that the lack of association with NMTC susceptibility in the Romanian cohort could be clarified by the differential distribution of these clinical parameters.

Additional analyses were performed to assess whether the selected polymorphisms are associated with clinical parameters including histology, TNM staging, cumulative RAI activity and remission rates. No statistically significant differences were observed, suggesting that $A K T 1$ polymorphisms are involved in tumor initiation rather than in processes of tumor progression, RAI therapy resistance and disease persistence.

Of note, with solid statistical significance the Romanian cohort received twice more low and medium RAI activities as compared to the Dutch patients, however is not associated with differences in remission rates. Again, this suggests that $A K T 1$ polymorphisms are involved in tumor initiation rather than in processes of tumor progression, despite the I-131 activities used for treatment. Also, there are differences in radiation exposure; Romania was among the countries affected by Chernobyl fallout and considering the average age of the Romanian patients ( $52 \pm$ S.D.) this would be interesting to be studied in relation to the $A K T 1$ polymorphisms.

By functional assays it was demonstrated that the AKT1 rs3803304 polymorphism, in contrast to the AKT1 rs2494732 and AKT1 rs2498804 polymorphisms, has a major effect on Akt phosphorylation, both in the naïve state and upon activation of the PI3K-Akt-mTOR pathway; cells bearing the heterozygous GC genotype, with the $\mathrm{C}$ allele conferring increased NMTC risk, exhibited elevated levels of phosphorylated Akt as compared to the GG genotype. These major functional consequences of the AKT1 rs3803304 polymorphism provides mechanistic insights into the observed genetic association. Furthermore, these findings support the current evidence that the PI3K-Akt-mTOR signaling pathway plays a major role in NMTC and could represent a promising strategy for targeted treatment $(5,19,25,36)$.

Previously, the AKT1 rs3803304 polymorphism has been demonstrated to also influence susceptibility, disease progression or clinical outcome of head and neck squamous cell carcinoma, lung carcinoma and esophageal carcinoma, indicating its major functional and clinical implications. In case susceptibility analyses were performed in these studies, the AKT1 rs3803304 minor allele was associated with increased cancer susceptibility in all, confirming the contribution of the minor $\mathrm{C}$ allele in the etiology of multiple cancer types $(28,31,32,37,38)$. Additionally to these reports, the present study provides mechanistic insights into the genetic association by linking the AKT1 rs3803304 minor $\mathrm{C}$ allele with elevated Akt phosphorylation. The exact biological consequences of the polymorphism and whether it promotes Akt phosphorylation or inhibits Akt dephosphorylation remains to be determined.

Although the heterozygous GC genotype, and most likely also the homozygous CC genotype, are demonstrated to predispose to development of NMTC by inducing hyperactivation of the PI3K-Akt-mTOR pathway upon the encounter of activating stimuli, it should be emphasized that this germline genetic variant is not capable of evoking thyroid tumorigenesis by itself because of limited genetic penetrance, but rather represents a risk modifier. Within the context of NMTC, these activating stimuli could range from growth factors to metabolites (e.g. lactate) and inflammatory molecules (e.g. danger-associated molecular patterns and pro-inflammatory cytokines) produced by the tumor microenvironment, triggering either receptor tyrosine kinases, metabolic receptors, toll-like receptors or cytokine receptors expressed by follicular thyroid (tumor) cells $(39,40,41)$.

In conclusion, the present study suggests that germline variants in the $A K T 1$ gene are an important risk factor in the etiology of NMTC, reinforcing the clinical utility of kinase inhibitors targeting the PI3K-Akt-mTOR pathway to abrogate pathological signaling driving the NMTC malignant process.

Supplementary materials

This is linked to the online version of the paper at https://doi.org/10.1530/ EC-20-0311. 


\section{Declaration of interest}

The authors declare that there is no conflict of interest that could be perceived as prejudicing the impartiality of the research reported.

\section{Funding}

This work was supported by the European Social Fund, Human Resources Development Operational Programme 2007-2013, project no. POSDRU/159/1.5/S/138776. T S P was supported by a Veni grant of the Netherlands Organization for Scientific Research (NWO; 016.136.065) and by the Alpe d'HuZes fund of the Dutch Cancer Society (KUN2014-6728).

\section{Ethics approval and consent to participate}

The study has been performed in accordance with the Declaration of Helsinki and approval was obtained from the Ethics Committees of Iuliu Hatieganu University of Medicine and Pharmacy Cluj-Napoca, Romania and Radboud University Medical Centre, Nijmegen, The Netherlands. Informed consent has been obtained from each patient or subject after full explanation of the purpose and nature of all procedures used.

\section{Consent for publication}

All authors are aware of and agree to the submission and all authors have contributed to the work described sufficiently to be named as authors. Any other person or body with an interest in the manuscript is aware of the submission and agrees to it.

\section{Availability of data and materials}

All raw data and study materials are available upon request.

\section{Author contribution statement}

T S P, M S P, T C and M J performed the experiments and data analysis. T S P, M S P, JW S, R N M, D P, C E G, T C and M J designed the study and wrote the manuscript. All authors read and approved the final manuscript. All authors had full access to all of the data in the study and take responsibility for the integrity of the data and the accuracy of the data analysis.

\section{References}

1 Jemal A, Bray F, Center MM, Ferlay J, Ward E \& Forman D. Global cancer statistics. CA: A Cancer Journal for Clinicians 201161 69-90. (https://doi.org/10.3322/caac.20107)

2 Kitahara CM \& Sosa JA. The changing incidence of thyroid cancer. Nature Reviews: Endocrinology 201612 646-653. (https://doi. org/10.1038/nrendo.2016.110)

3 Sanabria A, Kowalski LP, Shah JP, Nixon IJ, Angelos P, Williams MD, Rinaldo A \& Ferlito A. Growing incidence of thyroid carcinoma in recent years: factors underlying overdiagnosis. Head and Neck 2018 40 855-866. (https://doi.org/10.1002/hed.25029)

4 Wiltshire JJ, Drake TM, Uttley L \& Balasubramanian SP. Systematic review of trends in the incidence rates of thyroid cancer. Thyroid 201626 1541-1552. (https://doi.org/10.1089/thy.2016.0100)

5 Petrulea MS, Plantinga TS, Smit JW, Georgescu CE \& Netea-Maier RT. PI3K/Akt/mTOR: a promising therapeutic target for non-medullary thyroid carcinoma. Cancer Treatment Reviews 201541 707-713. (https://doi.org/10.1016/j.ctrv.2015.06.005)

6 Xing M. Molecular pathogenesis and mechanisms of thyroid cancer. Nature Reviews: Cancer 201313 184-199. (https://doi.org/10.1038/ nrc3431)
7 Dadu R \& Cabanillas ME. Optimizing therapy for radioactive iodinerefractory differentiated thyroid cancer: current state of the art and future directions. Minerva Endocrinologica 201237 335-356.

8 Nozhat Z \& Hedayati M. PI3K/AKT pathway and its mediators in thyroid carcinomas. Molecular Diagnosis and Therapy 201620 13-26. (https://doi.org/10.1007/s40291-015-0175-y)

9 Ngeow J \& Eng C. PTEN hamartoma tumor syndrome: clinical risk assessment and management protocol. Methods 2015 77-78 11-19. (https://doi.org/10.1016/j.ymeth.2014.10.011)

10 Orloff MS, He X, Peterson C, Chen F, Chen JL, Mester JL \& Eng C. Germline PIK3CA and AKT1 mutations in Cowden and Cowdenlike syndromes. American Journal of Human Genetics 201392 76-80. (https://doi.org/10.1016/j.ajhg.2012.10.021)

11 Pilarski R, Burt R, Kohlman W, Pho L, Shannon KM \& Swisher E. Cowden syndrome and the PTEN hamartoma tumor syndrome: systematic review and revised diagnostic criteria. Journal of the National Cancer Institute 2013105 1607-1616. (https://doi. org/10.1093/jnci/djt277)

12 Hou P, Liu D, Shan Y, Hu S, Studeman K, Condouris S, Wang Y, Trink A, El-Naggar AK, Tallini G, et al. Genetic alterations and their relationship in the phosphatidylinositol 3-kinase/Akt pathway in thyroid cancer. Clinical Cancer Research 200713 1161-1170. (https:// doi.org/10.1158/1078-0432.CCR-06-1125)

13 Abubaker J, Jehan Z, Bavi P, Sultana M, Al-Harbi S, Ibrahim M, Al-Nuaim A, Ahmed M, Amin T, Al-Fehaily M, et al. Clinicopathological analysis of papillary thyroid cancer with PIK3CA alterations in a Middle Eastern population. Journal of Clinical Endocrinology and Metabolism 200893 611-618. (https://doi. org/10.1210/jc.2007-1717)

14 Ibrahimpasic T, Xu B, Landa I, Dogan S, Middha S, Seshan V, Deraje S, Carlson DL, Migliacci J, Knauf JA, et al. Genomic alterations in fatal forms of non-anaplastic thyroid cancer: identification of MED12 and RBM10 as novel thyroid cancer genes associated with tumor virulence. Clinical Cancer Research 201723 5970-5980. (https://doi.org/10.1158/1078-0432.CCR-17-1183)

15 Landa I, Ibrahimpasic T, Boucai L, Sinha R, Knauf JA, Shah RH, Dogan S, Ricarte-Filho JC, Krishnamoorthy GP, Xu B, et al. Genomic and transcriptomic hallmarks of poorly differentiated and anaplastic thyroid cancers. Journal of Clinical Investigation 2016126 1052-1066. (https://doi.org/10.1172/JCI85271)

16 Murugan AK, Liu R \& Xing M. Identification and characterization of two novel oncogenic mTOR mutations. Oncogene 201938 5211-5226. (https://doi.org/10.1038/s41388-019-0787-5)

17 Cancer Genome Atlas Research Network. Integrated genomic characterization of papillary thyroid carcinoma. Cell 2014159 676-690. (https://doi.org/10.1016/j.cell.2014.09.050)

18 Schneider TC, de Wit D, Links TP, van Erp NP, van der Hoeven JJ, Gelderblom H, Roozen IC, Bos M, Corver WE, van Wezel T, et al. Everolimus in patients with advanced follicular-derived thyroid cancer; results of a phase II clinical trial. Journal of Clinical Endocrinology and Metabolism 2017102 698-707. (https://doi. org/10.1210/jc.2016-2525)

19 Plantinga TS, Heinhuis B, Gerrits D, Netea MG, Joosten LA, Hermus AR, Oyen WJ, Schweppe RE, Haugen BR, Boerman OC, et al. mTOR Inhibition promotes TTF1-dependent redifferentiation and restores iodine uptake in thyroid carcinoma cell lines. Journal of Clinical Endocrinology and Metabolism 201499 E1368-E1375. (https:// doi.org/10.1210/jc.2014-1171)

20 Hanly EK, Bednarczyk RB, Tuli NY, Moscatello AL, Halicka HD, Li J, Geliebter J, Darzynkiewicz Z \& Tiwari RK. mTOR inhibitors sensitize thyroid cancer cells to cytotoxic effect of vemurafenib. Oncotarget 20156 39702-39713. (https://doi.org/10.18632/oncotarget.4052)

21 Jin N, Jiang T, Rosen DM, Nelkin BD \& Ball DW. Synergistic action of a RAF inhibitor and a dual PI3K/mTOR inhibitor in thyroid cancer. Clinical Cancer Research 201117 6482-6489. (https://doi. org/10.1158/1078-0432.CCR-11-0933)

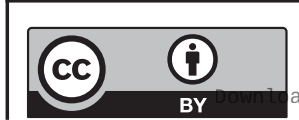

This work is licensed under a Creative Commons Attribution 4.0 International License. ded from Bioscientifica com at $04 / 26 / 2023 \quad 12: 42: 21 \mathrm{AM}$ 
22 Netea-Maier RT, Kluck V, Plantinga TS \& Smit JW. Autophagy in thyroid cancer: present knowledge and future perspectives. Frontiers in Endocrinology 20156 22. (https://doi.org/10.3389/ fendo.2015.00022)

23 Gonzalez E \& McGraw TE. The Akt kinases: isoform specificity in metabolism and cancer. Cell Cycle 20098 2502-2508. (https://doi. $\operatorname{org} / 10.4161 /$ cc.8.16.9335)

24 Wang J, Zhao W, Guo H, Fang Y, Stockman SE, Bai S, Ng PK, Li Y, $\mathrm{Yu} \mathrm{Q}, \mathrm{Lu} \mathrm{Y}$, et al. AKT isoform-specific expression and activation across cancer lineages. BMC Cancer 201818 742. (https://doi. org/10.1186/s12885-018-4654-5)

25 Souza EC, Ferreira AC \& Carvalho DP. The mTOR protein as a target in thyroid cancer. Expert Opinion on Therapeutic Targets 201115 1099-1112. (https://doi.org/10.1517/14728222.2011.594044)

26 Tirro E, Martorana F, Romano C, Vitale SR, Motta G, Di Gregorio S, Massimino M, Pennisi MS, Stella S, Puma A, et al. Molecular alterations in thyroid cancer: from bench to clinical practice. Genes 201910 709. (https://doi.org/10.3390/genes10090709)

27 Chen M, Gu J, Delclos GL, Killary AM, Fan Z, Hildebrandt MA Chamberlain RM, Grossman HB, Dinney CP \& Wu X. Genetic variations of the PI3K-AKT-mTOR pathway and clinical outcome in muscle invasive and metastatic bladder cancer patients. Carcinogenesis 201031 1387-1391. (https://doi.org/10.1093/carcin/ bgq110)

28 Hildebrandt MA, Yang H, Hung MC, Izzo JG, Huang M, Lin J, Ajani JA \& Wu X. Genetic variations in the PI3K/PTEN/AKT/mTOR pathway are associated with clinical outcomes in esophageal cancer patients treated with chemoradiotherapy. Journal of Clinical Oncology 200927 857-871. (https://doi.org/10.1200/JCO.2008.17.6297)

29 Li Q, Yang J, Yu Q, Wu H, Liu B, Xiong H, Hu G, Zhao J, Yuan X \& Liao Z. Associations between single-nucleotide polymorphisms in the PI3K-PTEN-AKT-mTOR pathway and increased risk of brain metastasis in patients with non-small cell lung cancer. Clinical Cancer Research 201319 6252-6260. (https://doi.org/10.1158/1078-0432. CCR-13-1093)

30 Pande M, Bondy ML, Do KA, Sahin AA, Ying J, Mills GB, Thompson PA \& Brewster AM. Association between germline single nucleotide polymorphisms in the PI3K-AKT-mTOR pathway, obesity, and breast cancer disease-free survival. Breast Cancer Research and Treatment 2014147 381-387. (https://doi.org/10.1007/s10549-0143081-9)

31 Pfisterer K, Fusi A, Klinghammer K, Knodler M, Nonnenmacher A \& Keilholz U. PI3K/PTEN/AKT/mTOR polymorphisms: association with clinical outcome in patients with head and neck squamous cell carcinoma receiving cetuximab-docetaxel. Head and Neck 201537 471-478. (https://doi.org/10.1002/hed.23604)

$32 \mathrm{Pu}$ X, Hildebrandt MA, Lu C, Lin J, Stewart DJ, Ye Y, Gu J, Spitz MR $\& \mathrm{Wu}$ X. PI3K/PTEN/AKT/mTOR pathway genetic variation predicts toxicity and distant progression in lung cancer patients receiving platinum-based chemotherapy. Lung Cancer 201171 82-88. (https:// doi.org/10.1016/j.lungcan.2010.04.008)

33 Bauerfeld CP, Rastogi R, Pirockinaite G, Lee I, Huttemann M, Monks B, Birnbaum MJ, Franchi L, Nunez G \& Samavati L. TLR4mediated AKT activation is MyD88/TRIF dependent and critical for induction of oxidative phosphorylation and mitochondrial transcription factor A in murine macrophages. Journal of Immunology 2012188 2847-2857. (https://doi.org/10.4049/jimmunol.1102157)
34 Ngkelo A, Meja K, Yeadon M, Adcock I \& Kirkham PA. LPS induced inflammatory responses in human peripheral blood mononuclear cells is mediated through NOX4 and Gialpha dependent PI-3kinase signalling. Journal of Inflammation 20129 1. (https://doi. org/10.1186/1476-9255-9-1)

35 Fagin JA \& Wells Jr SA. Biologic and clinical perspectives on thyroid cancer. New England Journal of Medicine 2016375 1054-1067. (https://doi.org/10.1056/NEJMra1501993)

36 Schneider TC, de Wit D, Links TP, van Erp NP, van der Hoeven JJ, Gelderblom H, van Wezel T, van Eijk R, Morreau H, Guchelaar HJ, et al. Beneficial effects of the mTOR inhibitor everolimus in patients with advanced medullary thyroid carcinoma: subgroup results of a phase II trial. International Journal of Endocrinology 20152015 348124. (https://doi.org/10.1155/2015/348124)

37 Le Rhun E, Bertrand N, Dumont A, Tresch E, Le Deley MC, Mailliez A, Preusser M, Weller M, Revillion F \& Bonneterre J. Identification of single nucleotide polymorphisms of the PI3K-AKTmTOR pathway as a risk factor of central nervous system metastasis in metastatic breast cancer. European Journal of Cancer $2017 \mathbf{8 7}$ 189-198. (https://doi.org/10.1016/j.ejca.2017.10.006)

38 Lopez-Cortes A, Leone PE, Freire-Paspuel B, Arcos-Villacis N, Guevara-Ramirez P, Rosales F \& Paz-Y-Miño C. Mutational analysis of oncogenic AKT1 gene associated with breast cancer risk in the high altitude Ecuadorian mestizo population. BioMed Research International 20182018 7463832. (https://doi.org/10.1155/2018/7463832)

39 Arts RJ, Plantinga TS, Tuit S, Ulas T, Heinhuis B, Tesselaar M, Sloot Y, Adema GJ, Joosten LA, Smit JW, et al. Transcriptional and metabolic reprogramming induce an inflammatory phenotype in nonmedullary thyroid carcinoma-induced macrophages. Oncoimmunology 20165 e1229725. (https://doi.org/10.1080/2162402X.2016.1229725)

40 Nicola JP, Velez ML, Lucero AM, Fozzatti L, Pellizas CG \& Masini-Repiso AM. Functional toll-like receptor 4 conferring lipopolysaccharide responsiveness is expressed in thyroid cells Endocrinology 2009150 500-508. (https://doi.org/10.1210/en.20080345)

41 Ward LS. Immune response in thyroid cancer: widening the boundaries. Scientifica 20142014 125450. (https://doi org/10.1155/2014/125450)

42 Guo Q, Lu T, Chen Y, Su Y, Zheng Y, Chen Z, et al. Genetic variations in the PI3K-PTEN-AKT-mTOR pathway are associated with distant metastasis in nasopharyngeal carcinoma patients treated with intensity-modulated radiation therapy. Scientific Reports $2016 \mathbf{6}$ 37576.

43 Lee SY, Choi JE, Jeon HS, Choi YY, Lee WK, Lee EB, et al. A panel of genetic polymorphism for the prediction of prognosis in patients with early stage non-small cell lung cancer after surgical resection. PloS One 201510 e0140216

44 Wang Y, Lin L, Xu H, Li T, Zhou Y, Dan H, et al. Genetic variants in AKT1 gene were associated with risk and survival of OSCC in Chinese Han population. Journal of Oral Pathology Medicine 201544 $45-50$.

45 Kim MJ, Kang HG, Lee SY, Jeon HS, Lee WK, Park JY, et al. AKT1 polymorphisms and survival of early stage non-small cell lung cancer. Journal of Surgical Oncology 2012105 167-174.

46 Shao J, Li Y, Zhao P, Yue X, Jiang J, Liang X, et al. Association of mTOR polymorphisms with cancer risk and clinical outcomes: a meta-analysis. PloS One. 20149 e97085.

Received in final form 7 July 2020

Accepted 2 October 2020

Accepted Manuscript published online 5 October 2020 https://ec.bioscientifica.com https://doi.org/10.1530/EC-20-0311 (c) 2020 The authors Published by Bioscientifica Ltd

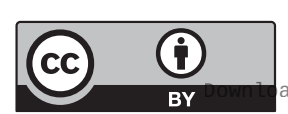

This work is licensed under a Creative Commons Attribution 4.0 International License. ded from Bioscientifica.com at 04/26/2023 12:42:21AM 